Article

\title{
Implementing Reflective Group Work Activities in a Large Chemistry Lab to Support Collaborative Learning
}

\author{
Hannah Leopold ${ }^{1, *}$ and Ann Smith ${ }^{2, *}$ \\ 1 Department of Chemistry, College of Science and Engineering, Twin Cities, University of Minnesota, \\ Minneapolis, MN 55455, USA \\ 2 Internationalizing the Curriculum and Campus, Global Programs and Strategy Alliance, Twin Cities, \\ University of Minnesota, Minneapolis, MN 55455, USA \\ * Correspondence: leopo023@umn.edu (H.L.); annsmith@umn.edu (A.S.)
}

Received: 1 December 2019; Accepted: 26 December 2019; Published: 27 December 2019

\begin{abstract}
Many classrooms in higher education are becoming increasingly diverse. Diversity is an asset when student interactions are promoted and facilitated by instructors. The challenge is, many times students are grouped together for a collaborative project without attention to or skilled support for the learning and development that can occur through the intercultural collaborative process itself. Instructors often assume this learning happens automatically or organically and does not need to be acted upon explicitly. However, collaboration skills do not come naturally; simply putting students in groups is not enough. When collaboration is facilitated skillfully it benefits all students, especially those from marginalized and historically underserved groups. Here, we enumerate barriers instructors face in supporting groups, describe/share a model, and explore the implementation of this model in a general chemistry lab, which relies heavily on group work. We found that these activities are feasible in a large STEM class, that students participated and found value in them, and that they enhanced students' content learning and the development of cross-cutting competencies sought by employers. We hope after reading this paper, instructors will recognize the responsibility and opportunity they have in supporting interactions, and have new inspiration and a pathway to do so.
\end{abstract}

Keywords: collaborative learning; undergraduate general chemistry; group work; inclusive pedagogy

\section{Introduction}

Many STEM courses that rely on high stakes, long term group work offer tremendous opportunity for students from all backgrounds to come together around common goals. This form of collaborative learning (CL) allows students to actively engage with the course content and one another. This collaborative process has the potential to enhance content learning and promote the development of transdisciplinary competencies that institutions of higher education (HE) promise their graduates, and that industry seeks out in prospective employees [1]. Unfortunately, the reality is that the learning potential of collaboration is not leveraged to its fullest in the classroom [2].

Large STEM labs often use group work because it is a well-documented method for learning complex concepts and skills [3,4]. Group work is also utilized as a way to manage exceedingly large numbers of students and efficiently allocate limited time, space, and equipment. Grouping students is often sufficient to address these course management and logistical matters, however, it is only one step in a larger pedagogical process necessary to achieve the full potential of student interactions [5]. Yet, putting students into groups is often the only step many instructors take before asking them to complete a task. This is problematic because skills and attitudes necessary for effective collaboration do 
not come naturally to students [6,7]. Therefore, facilitating the development of these skill-sets becomes an added opportunity and responsibility of instructors who use group work as a teaching and learning method. Facilitating this development is not easy and there are both real and perceived barriers. Instructors need, and are seeking, support to develop their own facilitation skills and confidence to do CL well [7-9].

In this paper, we will enumerate these barriers, and explore one model that was implemented in a large STEM course, a General Chemistry (genchem) lab. This model provided the scaffolding and support steps known to enhance group functioning, group experience, and group learning (of content and broader competencies). These course revisions allowed the program and the instructors to leverage more of the potential benefits of $\mathrm{CL}$, and avoid the pitfalls. With this article, it is our hope instructors will see new and feasible pathways and find inspiration to integrate these activities or seek out other approaches from the many resources available for their own unique learning context.

\subsection{What Is Collaborative Learning and Why Is It So Important to Get It Right?}

Collaborative learning is characterized by more than one individual working on a shared task, with shared goals, and where students must depend on one another in order to successfully complete a task $[10,11]$. CL is a form of active learning, where all students are engaged in the learning process as opposed to passively taking in information. It is understood that when conditions are right, the learning benefits are greater for those working collaboratively than those working alone or competitively $[10,12,13]$. Johnson and Johnson outline three goal structures-competition, independent tasks, and cooperation. Of the three, they suggest cooperation should be used the majority of the time because social interdependence is "one of the most fundamental and ubiquitous aspects of being human and it effects all aspects of our lives ... " [14] (p. 4). Our personal, academic, and professional success is dependent on the knowledge, skills, and attitudes we acquire by interacting effectively with others.

The potential benefits of CL have been documented for decades, and there are many. Between Johnson [15] and Panitz [11] over 50 benefits were identified. Laal and Ghodsi organized these 50 benefits into four categories: social, psychological, academic, and alternate assessment techniques [16] (pp. 487-88). The goal of this paper is not to recreate another inventory of the benefits, but we would like to enumerate those that are particularly relevant to this work under three of the categories, and draw on references from multiple fields of study-multicultural, intercultural, international, curriculum, and instruction, etc. Although we do not expand on the category of assessment, we acknowledge its importance.

Social benefits

- $\quad$ promotes intercultural and interpersonal skill development [9,17-22];

- fosters a sense of community and support among peers [23,24];

- increase students' social networks [14,22];

- encourages democracy outcomes such as: perspective taking, civic engagement, racial/cultural engagement, and compatibility of difference [25].

Psychological benefits

- reduces general classroom [26] and test-taking anxiety [11,15];

- improves self-esteem [27] and self-efficacy [28];

- advances emotional maturity, well-adjusted social relations, trust, and optimism about people [14].

Academic benefits

- causes deeper and more sophisticated mastery of course content [14,29,30];

- improves academic performance [13,31,32];

- improves retention and transfer of new information [33];

- $\quad$ enhances problem solving and critical thinking skills [20,21,25,29,34]. 
Some of the benefits outlined above, promote an overall sense of inclusion and belonging which is exceptionally significant because it is a prerequisite for students' learning and persistence $[35,36]$. The benefits that promote this include greater intercultural and interpersonal skill development, a sense of community and support among peers, and increase students' social networks. Casey and Murphy Robinson study the neuroscience of inclusion, and report that, "A feeling of belonging and being a valued member of the group is not just nice to have; it is a brain requirement for survival and to feel and operate at our best" [37] (p. 12). Many institutions in the US and across the world are seeking to increase diversity in higher education and therefore have a responsibility to build institutional capacity that establishes inclusive environments and facilitate meaningful interactions between diverse students [38,39]. CL is one clear way to support these efforts. These efforts are also shown to support institutional goals related to retention rates and persistence [12].

Further, as institutions of higher education seek to grow the diversity of their campuses, traditional pedagogical practices need to be reassessed in terms of who benefits from them and who does not. Collaborative learning is one way in which we can adapt. Research suggests that when done well, collaborative learning benefits all students, especially those who are marginalized, underrepresented, and historically underserved $[2,12,40]$. This is especially important in the STEM fields, which are known to have lower persistence rates for women [12,41], first generation [42,43], and students of color [6,44-47]. This increased diversity is a resource and an asset to university campuses and classrooms, and when engaged can further expand learning potential $[7,9,22,25,29,48]$. Interaction through group work with students from diverse backgrounds and lived experiences adds a dimension to the group in which students may experience disequilibrium as their worldviews may be challenged in ways they have not been before. Disequilibrium is required for growth and development to occur $[49,50]$. Johnson and Johnson have noted that added benefits of diverse groups is due to an exposure to a wider variety of ideas, multiple perspectives, and different approaches to problem solving which helps stimulate students' learning, creativity, and cognitive and social development [10]. This is borne out in research across multiple disciplines and numerous studies.

Based on this literature, CL has the potential to greatly increase students' disciplinary knowledge and support the development of the competency-based Essential Learning Outcomes (ELO) that are critical for industry [51]. The ELOs outlined by the American Association of Colleges and Universities were established in partnership with US higher education and industry leaders and align with the benefits of CL above. The ELOs include inquiry and analysis, critical and creative thinking, teamwork and problem solving, civic knowledge and engagement, and intercultural knowledge and competence. These skills and competencies are highly sought after by today's employers, "employers overwhelmingly endorse broad learning and cross-cutting skills as the best preparation for long-term career success," and yet many are finding the current graduates do not have them [1]. Therefore, if we want to prepare our graduates to work in an increasingly diverse society, we need to leverage these benefits of CL and leverage them well.

From an institutional perspective, colleges and universities also benefit when instructors emphasize both the process and product of group work. In internal and in public facing documents, institutions are communicating to their stakeholders (students, community, industry partners) that graduates from their institutions will have the skills and knowledge necessary for the 21st Century realities and demands. The benefits of collaborative learning help universities fulfil promises, such as that which is articulated in the University of Minnesota's Board of Regents Policy Mission Statement which is the institution at which this study was conducted [52]:

Teaching and Learning - To share that knowledge, understanding, and creativity by providing a broad range of educational programs in a strong and diverse community of learners and teachers, and prepare [students], for active roles in a multiracial and multicultural world.

Given all the immense benefits, it is important to facilitate collaborative learning, and to do it right, or the potential is not achieved. If student interactions are not supported there can be negative 
effects, such as students preferring to work alone because they have had negative previous group work experiences [53-55]. The consequences of this can vary. Not only do they not want to participate in a process that promotes their learning, this attitude can also reinforce stereotypes and cause marginalized students to be further marginalized. In high stakes situations it also causes increased stress, and reduced performance. Skillfully facilitating CL and student interactions can both leverage the potential of this pedagogical method and avoid the negative consequences that can arise if students are not supported. This is an existing and ongoing challenge for educators. However, louder calls for inclusive and equitable practices that support learning of all students in STEM and increasing diverse student populations (in all forms), intensifies the need and urgency to adopt effective collaborative learning practices.

\subsection{Barriers to Implementing Collaborative Learning}

Even with decades of scholarship on the positive outcomes of $C L$ it is still being underused and underleveraged in higher education [2,16,30]. When referring to the benefits of $C L$, we used qualifying language such as "potential" and "when done right", very deliberately. In order for these benefits to accrue, interactions among students needs to be intentionally and skillfully facilitated by an instructor. This condition must be met and emphasizes the critical role that instructors play in the effectiveness of $\mathrm{CL}$. Thus, if there are so many benefits of collaborative learning and instructors have a critical role in achieving these benefits, why is it not being done? Here we will take a close look at the real and perceived barriers to fostering effective collaborative learning.

The first barrier is the assumption that students will inherently learn the skills associated with collaborative learning just by being placed in a group. Chang et al. calls this "magical thinking" [56]. Student interaction and the skills and attitudes associated with collaboration do not come naturally to us $[57,58]$. This is especially true when we are interacting with diverse others which we know is the reality of our classrooms. Intercultural communication and teamwork skills are something that needs to be taught, practiced, and modeled $[7,10,58]$. Therefore, simply putting students into groups is not enough. This magical thinking is just one of the barriers that keeps instructors from providing the scaffolding and support that $C L$ requires.

Another barrier is a culture in HE that is content-centered versus student-centered. When departments or institutions have a content-heavy emphasis, instructors feel pressured to get through content which does not motivate them to take on the complex task of designing and facilitating student interactions. In our work, we have heard from STEM instructors that this focus on disciplinary knowledge is valid and that it is not their job to teach such skills. For instance, supporting the development of the bigger university goals such as the competency associated with "being active in a multiracial and multicultural world" is the responsibility of liberal education [52]. On the contrary, all instructors in the US across all disciplines are called upon to support the development of the Essential Learning Outcomes [51]. There is no one class that teaches these competencies but rather students develop these competencies only when they are given frequent and quality opportunities to interact with others, to practice and reflect on them, and very importantly, when they see them modeled $[7,25,59]$. Lee et al. contend that no course, including STEM courses, are excused from this responsibility, and in every course there is a responsibility and an opportunity [7].

For instructors that do recognize the need to support groups, we often hear that they do not know what activities to implement or how to facilitate them, and that they are worried about doing it wrong. This lack of knowledge and confidence is not unfounded, because instructors in higher education are often hired on the basis of expertise in their disciplinary field. As a result, faculties do not always have formal training in how to teach, and they may simply replicate techniques from how they were taught $[60,61]$. Establishing inclusive environments and promoting, facilitating, and supporting student interactions is a separate area of expertise that needs to be developed by the instructor through practice and reflection $[7,14]$. As in many disciplines, STEM instructors are often not given the opportunity to hone these group facilitation skills because they are restricted by their disciplinary curriculum and lack 
of time. Recently published articles are evidence that these skills remain an area in which instructors need and are seeking institutional support [7,8,16,22,62].

Teaching in higher education is known to be a very solitary activity. It is rare for instructors to come together to discuss the challenges they are facing, areas they are stuck, successes they have experienced, concerns about students, and, overall, simply building community and support [63]. This presents another roadblock. Faculty Learning Communities (FLC) offer further rationale, guidance, models, and outcomes of such groups [64]. In 2017-2018, the authors along with the director of the genchem program, and three other faculty from different disciplines came together as a form of FLC, meeting every few weeks [65]. It was through these conversations that a strong community was established, friends were made, and the model described here was initiated.

These barriers are outlined to raise awareness of the real roadblocks that are either built into the very structure or are part of the culture of higher education, and to acknowledge these and encourage instructors to own what might be keeping them from further honing their skill as it relates to their role as facilitators of student interactions. We encourage instructors to reflect on their teaching practice, identify strengths, and where they can further develop their craft, seek out a community of practitioners, and take advantage of institutional resources for teaching and learning. To have sticking points or questions about different aspects of teaching should not be internalized as a deficit. Owning this, and continually reflecting on, revising, trying new techniques, and starting the cycle over in order to get "unstuck" is the restlessness that good teaching requires [7].

The way in which the genchem team (Michelle Driessen, director, and Hannah Leopold, assistant director) approaches their practice is indeed restless and iterative. Collaborative learning is just one of the current areas of focus for the genchem program as a whole, and this follows a pattern of restlessness that has been characteristic of the team's approach from the beginning. On that note, we will move on to describe the course environment in which we integrated the evidence-based practices that emphasize the process (as well as the product) and allowed us to leverage the learning that can come of it.

\subsection{Our Contribution to the Conversation}

The case we examine here is a general chemistry, problem-based lab course that enrolls approximately 3500 students each academic year. Roughly one third of the student body take the lab before graduation making it a very large course with many complexities. In the lab, students who are primarily first or second year university students are assigned to groups of 3-4. Since the lab is problem-based, these student groups must rely on each other to write experimental plans and summaries, conduct experiments, and give presentations on their results. Students work in the same group all semester and are expected to come to lab prepared, and ready to apply and learn scientific concepts and skills through a collaborative experimentation process. About $70 \%$ of the students' grade depends on the quality of their group work, as opposed to individual work. Therefore, for many, how they perform as a group will affect their success in the class. Students' success in the genchem lab and course have broader, significant implications for their futures, including the degree they end up with and ultimately their career options.

Like many lab courses, the learning objectives in our syllabus explicitly state that students will "learn to work effectively in a group" and "reflect on the learning process ... ". However, like much of the research suggests, we initially assumed that students would learn the skills necessary to work together effectively just by putting them into groups. We also assumed that students had already developed these skills in high school. However, time and time again, we found ourselves having conversations with students about group dynamic concerns including feeling marginalized, left out, and stressed. These conversations also extended to our 19 different teaching assistants who were unsure of how to manage these issues. At times, these conversations consumed the same amount of time as conversations regarding content and academic performance. This signaled to us that students were having negative group experiences that were impacting their learning and that they did not feel a 
sense of agency over their group dynamics. As restless practitioners, this sparked the conversation of "so what are we going to do about it?".

Based on these experiences, we started to recognize the importance and need to facilitate and support student groups. With the help of a faculty cohort, we gathered information through observing each other's classrooms, reviewing research, and discussing how we could establish an environment for positive interactions [65]. Next, we identified evidence-based steps to improve the group outcomes and experiences. We also ensured that stated course learning outcomes, activities, and assessment aligned. We had to be realistic in our approach, making sure that that the new activities/elements could feasibly be integrated into the unique lab curriculum and learning environment. In this article, we will only be focusing on two of the reflective group activities, Group Check-in \#1 and \#2, however we want to position them within the broader context of all the course revisions that contributed to their implementation and effect. The activities were selected because they fit within the existing lab course structure and, more importantly, because they facilitate conditions that must be met for CL benefits to be realized. Johnson and Johnson have identified these as positive interdependence, promotive interaction, individual accountability and responsibility to achieve group goals, frequent use of interpersonal and team work skills, reflection on the current functioning of the group to improve the group's effectiveness [14].

Activities and conditions for effective collaboration:

- Provided explicit written and verbal language on the importance and relevance of group work for personal growth as well as success in the course, other courses, and their futures.

- On the first day of class, activities were facilitated to promote rapport among group members. Newly assigned/established groups were given time to (1) do an ice breaker where they were asked to introduce themselves, then identify five things they have in common and one thing that is unique about each individual member (2) discuss their experiences with both positive and negative group work experiences, and what they attributed the nature of those experiences to (3) set expectations they have for one another and establish (in writing) their group's policies.

- Group Check-in \#1: After the first three-week experiment and subsequent group presentations, groups were given time to address and submit responses to the following prompts:

What is the one change your group will make to improve your performance?

It is easy to identify what you need to change but harder to identify how to fix it. Therefore, what is your group going to DO to solve the problem or improve?

- Group Check-in \#2: After the second two-week experiment and presentations, groups were given time to address and submit responses to the following prompts:

What did you do to implement your plan of improvement?

IF you implemented the plan: What specific effect did this have? Give examples. Are there any additional changes you think your group needs to make?

- After each experiment, students submitted graded self and peer evaluations where they were asked to reflect on their own contributions and the contributions of their group members.

- On the last day of class, student completed an individual reflection on what they learned about themselves and about group work. We also asked them to reflect on what skills they learned that are transferable to other settings.

In this article we explore various aspects of Group Check-ins 1 and 2. The research questions we investigate are: (1) Is implementing support for positive student interaction feasible in a large STEM course? (2) Whether or not students engage and see value in the activities, in a STEM context? (3) If so, in what ways do the activities enhance learning and development around chemistry and collaboration as articulated by the students? (4) What can we learn as instructors about our students' struggles and strengths? 


\section{Materials and Methods}

\subsection{Participants}

The study participants were drawn from students who were enrolled in the general chemistry I lab course during the spring 2019 semester. There were a total of 795 students enrolled. All students were exposed to the activities and assigned to groups of 3-4. We applied a stratified random sampling scheme in order to account for variations across lab sections such as implementation fidelity and instructor approach so as to gain as representative a sample as possible. We stratified by individual instructors teaching the course which included undergraduate teaching assistants (TAs), graduate TAs, and teaching specialists. One student group from each instructor's lab sections was randomly selected. During spring 2019, we had 19 unique instructors teaching the course therefore we selected 19 groups, for a total of 76 students. We anticipated that 19 groups would meet the criteria for data saturation $[66,67]$.

\subsection{Material}

In this case, the genchem team (Michelle Driessen, director, and Hannah Leopold, assistant director) introduced a sequence of new activities in order to establish/facilitate the conditions noted above. Dedicated time and space was provided for student groups to reflect on how their group was functioning. These reflections asked students to identify what their group was struggling with, what they can and will do to address this struggle. The complete prompts students were given can be found in Appendix A. Check-in \#1 was completed after the first three-week experiment and Check-in \#2 after the second two-week experiment. The materials studied were the qualitative responses to these reflection activities that each group submitted. Although dedicated time was set aside for these group check-ins, students were made aware that they would not be graded on the check-ins. Students were also given an end-of-semester evaluation that included two Likert scale questions asking them to rate aspects of their experience with the two check-in activities.

\subsection{Data Analysis}

With Institutional Review Board (IRB) approval (STUDY00007096), under the category of educational research, we examined existing documents which include the individual group responses to the prompts for Check-ins 1 and 2 (see Appendix A) and the end-of-year evaluation. This IRB did not allow publication of students written responses to the check-ins.

Qualitative data was the primary source for analysis, as we wanted to capture the students' experiences with and responses to the activities that cannot be gleaned from quantitative data alone. The authors initially established a data analysis plan. Our approach to data analysis aligned with grounded theory, and followed the steps outlined by Strauss and Corbin [68] whereby we approached the data openly in order to see what patterns/themes emerged. Data was coded, categorized, and organized into themes, as they developed through this iterative process. Inter-rater reliability was attained, as the researchers established the coding process jointly, then independently reviewed, coded, and thematized the data. Any disagreements were resolved by discussion and consensus. Quantitative data was gathered via the end-of-semester evaluations and quantifying aspects of the qualitative data, and was used to provide answers to research questions 1 and 2 as well as for the purpose of data triangulation [69].

\subsection{Limitations}

The main limitation to this study is its generalizability. With a focus on one course, in one institution, the findings are only representative of this course. There are also limitations to the responses we coded from students. For Check-in \#1 students were asked to identify one change they planned to make. From these changes, we had to infer when coding what the students or groups were struggling with. Additionally, the two check-ins asked students to reflect on the questions and then 
discuss what they wrote. Therefore, we had to assume that the responses students submitted for these activities was the same as what they discussed as a group. Finally, we were unable to determine if and who the activities supported most because we were unable to obtain data through formal institutional channels regarding our students' information such as gender, race, socioeconomic, visa status.

\section{Results}

\subsection{Students' Participation in the Group Activities}

Although the group check-ins were not mandatory nor graded activities, 18 out of 19 groups (95\%) willingly participated and responded to the questions that were asked. Only one group contributed minimally to the activity. We defined participation as the submission of one or more responses from the members of the group. Due to the way in which the instructions were phrased, we found that some groups submitted one response that represented the group's reflection while others submitted individual responses that were then discussed within the group.

\subsection{Self-Identified Group Challenges and Struggles}

Table 1 below represents the five themes that emerged when groups were asked about what changes they would make to improve for the next experiment. Based on students' responses, we inferred what the group was struggling with. Many groups identified more than one struggle which is captured in Table 1. Unsurprisingly, being unprepared and communication difficulties were the most common barriers with over half of the groups identifying these struggles.

Table 1. Themes that emerged when groups were asked about what they were struggling with and the number of groups that identified the respective theme of the 18 groups that participated.

\begin{tabular}{|c|c|c|}
\hline Themes & Examples & Number of Groups \\
\hline Unprepared & $\begin{array}{l}\text { - } \quad \text { Less procrastinating } \\
\text { - } \quad \text { Prepare ahead of time }\end{array}$ & 10 \\
\hline Communication & $\begin{array}{ll}\text { - } & \text { Better communication } \\
\text { - } & \text { More communication } \\
\text { - } & \text { Talk about problems }\end{array}$ & 10 \\
\hline Unequal workload/unclear roles & $\begin{array}{l}\text { - } \quad \text { Need to divide and conquer } \\
\text { - } \quad \text { Split work evenly }\end{array}$ & 7 \\
\hline Lack of coordination & $\begin{array}{l}\text { - } \quad \text { Unorganized } \\
\text { - } \quad \text { Do not understand or agree with what is being done }\end{array}$ & 6 \\
\hline Poor time management & $\begin{array}{ll}\text { - } & \text { Be more efficient } \\
\text { - } & \text { Multitask }\end{array}$ & 5 \\
\hline
\end{tabular}

One thing we would like to acknowledge is how interrelated the themes are to one another. For example, a lack of communication may cause unclear roles and being unprepared will likely cause poor time management. However, we found it important to distinguish these themes and capture students' responses authentically. Hence, to distinguish between unprepared and time management, we considered one to be group work outside of lab and the other within, respectively.

\subsection{Group Identified Strategies to Overcome Challenges}

As identifying a struggle does not mean it will be fixed, we asked groups to identify a specific strategy that they will use for the next experiment that will help them overcome their challenge(s) (Table 2). Again, we found that groups identified multiple strategies. Seven themes emerged with group preparation being the most common. Since labs meet once a week, many groups expressed the need to meet outside and establish a plan so that they could come into lab prepared. We distinguished this group preparation from individual preparation where students mentioned they needed to review the experiment and material so that they could personally contribute more to the group. The other 
commonly identified strategies were establishing a communication plan and explicitly assigning roles. Of the groups that identified a challenge, all of them were able to decide on a strategy or set of strategies to help them be more successful as a group during the next experiment.

Table 2. Strategies students identified to overcome group challenges and the number of groups that identified the respective theme of the 18 groups that participated.

\begin{tabular}{|c|c|c|}
\hline Themes & Examples & Number of Groups \\
\hline Group preparation & $\begin{array}{l}\text { - } \quad \text { Meet outside of lab } \\
\text { - } \quad \text { Come in with a plan } \\
\text { - } \quad \text { reate a shared document }\end{array}$ & 11 \\
\hline Establish a communication plan & $\begin{array}{l}\text { - } \quad \text { Create a group chat/text } \\
\text { - } \quad \text { Ask questions }\end{array}$ & 9 \\
\hline Establish roles and accountability & $\begin{array}{l}\text { - } \quad \text { Assign roles and jobs } \\
\text { - } \quad \text { Divide responsibilities }\end{array}$ & 9 \\
\hline Individual preparation & $\begin{array}{l}\text { - } \quad \text { Study material beforehand } \\
\text { - } \quad \text { Review experiments before lab }\end{array}$ & 5 \\
\hline Inclusion & $\begin{array}{l}\text { - } \quad \text { Listen to others } \\
\text { - Give everyone a chance to speak }\end{array}$ & 3 \\
\hline Time Management & $\begin{array}{l}\text { - Use time better } \\
\text { - } \quad \text { Pay attention to time }\end{array}$ & 3 \\
\hline Proofread & $\begin{array}{l}\text { - } \quad \text { Double-check data } \\
\text { - } \quad \text { Peer evaluate assignment }\end{array}$ & 2 \\
\hline
\end{tabular}

\subsection{Effects of Identified Strategies}

After students completed their first group check-in, they performed another experiment over the course of two weeks where they had a chance to employ their new strategies. They then gave a 5-10 min group presentation on their results and conclusions of their experiment. Once students completed their experiment and presentation, we provided another opportunity for the groups to reflect on whether their strategies had an effect(s) and in what way(s). The themes of these effects are summarized in Table 3.

Table 3. The effects strategies had on their group's dynamic and performance and the number of groups that identified the respective theme of the 18 groups that participated.

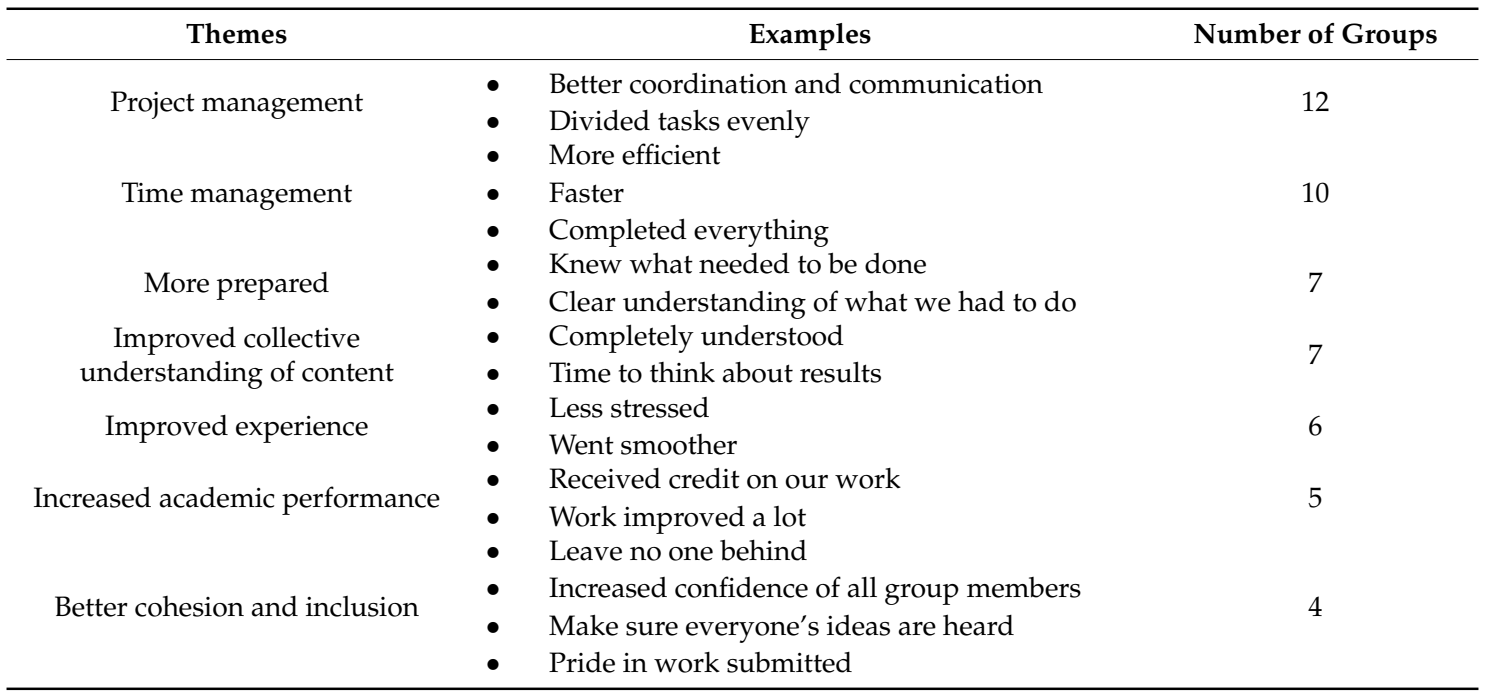

While coding the responses for all the check-ins of the 19 groups selected, data saturation was reached. No new themes emerged, therefore, we concluded that no further data collection and analysis was needed. 


\subsection{Responses to End of the Semester Evaluations}

On the end of semester evaluations that were administered once the course had concluded, we asked students to provide feedback on the value of group work and the activities. In Figure 1 below, $74 \%$ of the students that were selected for this study agreed or strongly agreed that they learned valuable skills by working in a group that could be applied outside of chemistry.

A.

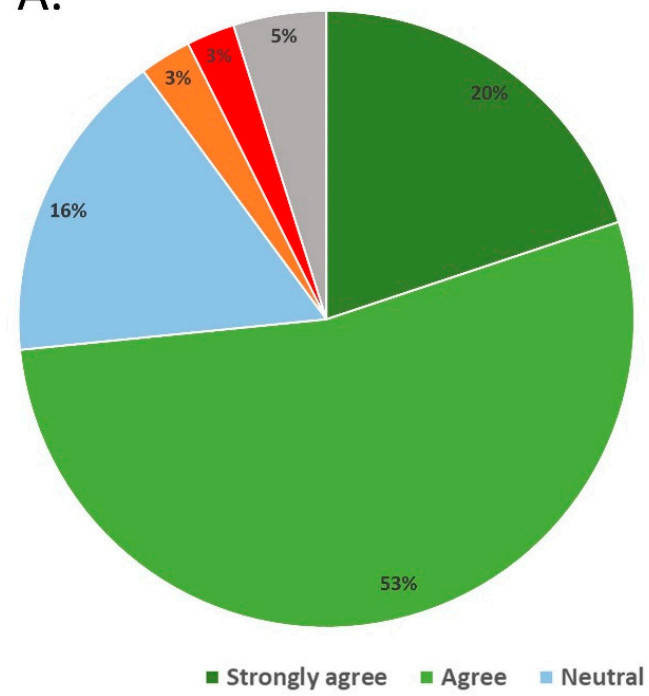

B.

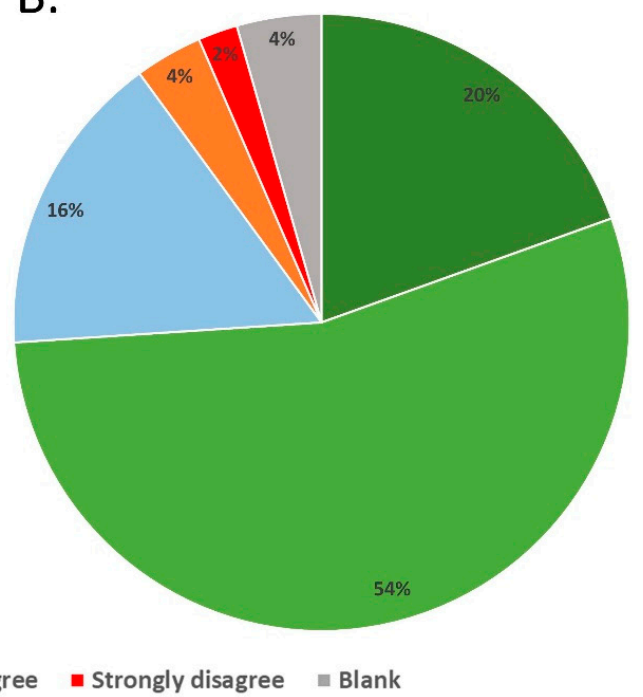

Figure 1. Students' response to "I believe I learned valuable skills by working in a group this semester that can be applied outside of chemistry". (A) Students' responses from the whole course. (B) The responses of the 19 groups selected for this study.

Although we cannot directly attribute the skills learned to the group activities, we did ask students to report on if they found the activities worthwhile and if they would recommend continuing them. Students' responses to this statement are seen in Figure 2 with $58 \%$ of students selected agreeing or strongly agreeing.

A.

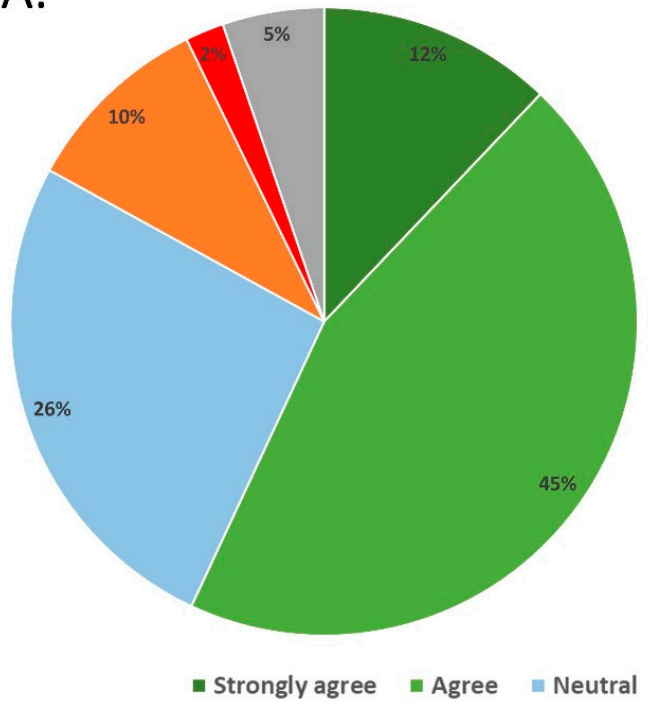

B.

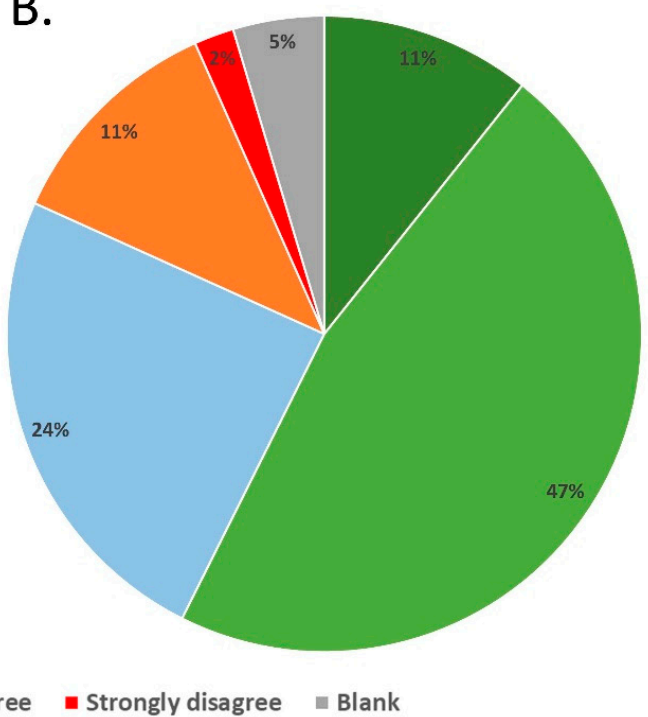

Figure 2. Students' response to "Overall, I think the group activities are worthwhile and I would recommend continuing them for future semesters". (A) Students' responses from the whole course. (B) The responses of the 19 groups selected for this study. 


\section{Discussion}

\subsection{Are These Activities Feasible in A Large General Chemistry Lab?}

We explained much of the genchem course context earlier, which includes many moving parts and complexities, so we believe it is worthwhile to reflect on the feasibility of this type of intervention for a course like this. We found that the activities are feasible and not as add-ons but integrated seamlessly into the existing course structure and design. These two points are critical. So how did we make it feasible without overhauling a large complex course? First, the genchem team identified a gap between an already articulated learning outcome (learn to work effectively in a group) and instructional activities to achieve the outcome. Next, the team intentionally designed activities to facilitate and assess this outcome. As we were planning the intervention, the genchem team reviewed the lab calendar and identified two blocks of $20 \mathrm{~min}$ that were observed as underutilized in previous semesters. There are three days each semester when groups present on their experiments. These presentations do not take the full class time, so the remaining time was selected for the group reflection activities, as they did not take time away from experiments and they immediately followed the completion of a big collective effort. To answer our first research question, we demonstrated that integrating an additional course element to facilitate improved group functioning, group experience, and learning is feasible for busy instructors in large complex course. We also showed that the activities can be integrated into the existing course structure. This integration is important because when they are seen as add-ons, the instructors and students will be less invested in the activities making them less effective and sustainable.

\subsection{Did the Students Participate in the Activities?}

This brings us to the discussion of our second research question, did the students participate in the activities? This was an important question for us to ask, as it is a new element of the course and for many, is not expected in STEM. Additionally, the activities were not required or graded so groups could have opted out, packed up, and left the lab without any negative consequence to their grade. However, 18 of the 19 groups we studied utilized the time they were given to complete the activity and submit their responses. They also followed through with their strategies. Check-in \#1 asked them to identify one way they can improve their group functioning and what they will do to make that improvement. The second activity, 4 weeks later, prompted students to reflect on if they carried out their strategy and if so, to what effect. Again, all but one group identified a strategy and implemented it, and submitted their second group reflection assignments online.

We attribute this level of participation to a number of intentional implementation decisions. First, the instructors allocated class time for students to complete the activities. How instructors use their limited class time signals to students what they value and what is important for success in the class. Second, the rationale on the importance of the activities was made explicit in written and verbal communication. These messages made it clear why the activities were relevant to their success in the course, their personal growth, and to their career readiness. On the first day of lab, the following was communicated to students "Employers are looking for graduates who have skills necessary to work effectively in diverse groups. Since you will be working in your group for 14 weeks this semester, this is a great opportunity to learn, practice, and reflect on how to work with others who may think differently than you." Explicit statements such as this are considered effective practice for good teaching [70]. Third, from the genchem team, they received a message of genuine care and interest in their success not only as chemistry students, but as humans.

How the activities were worded was also intentional and may have had an effect on students' motivation to complete them. We wanted to normalize the idea that group work takes effort, and that they have agency in the success/failure as well as the nature of their group experience (positive or negative). Therefore, we did not ask if they had a challenge or improvement to make, rather, we built that assumption into the prompt by asking students what change they will make. This emphasized 
that all groups have challenges and that working with others requires reflection and skill and that those skills need to be practiced. Another reason this activity was taken seriously by students may have had to do with the timing of it. They were asked to do them immediately following their group presentations, so it was an ideal time to come together as a group to debrief and move into a proactive mode of reflection and improvement.

Finally, implementation fidelity on the part of the instructor is an important aspect of the activities' success. When investigating why one group did not complete the activities, we found that the majority of this group's section did not participate in them. In general, when we looked across all 30 sections, the completion or lack of, was dependent on the instructor. This suggests that some lab instructors either did not ask the students to do these activities, did not give them class time to do them, or did not convey the value and rationale for them, as they were instructed to do. This offers valuable insight and a need for further conversation, training for and "buy-in" from instructors. These findings support the literature that facilitating student interactions requires instructors' attention and is a skill-set that instructors need to be taught. For the authors, we have made note of this for the next iteration of the intervention and the next TA orientation and training.

\subsection{Is There Evidence That This Process Enhanced Learning and Development Around Chemistry, Group Work Skills, and Did It Improve the Group Experience?}

As practitioners, we ultimately wanted to know if the group check-ins enhanced the learning and development of the students. This question can largely be answered by considering the strategies and their effects that students reported in Tables 2 and 3. Every group that responded to the check-ins established a specific strategy(s) to address what their group was struggling with. Of the top three strategies, all relate in particular to group work skills including preparing as a group, establishing a plan for communication, and assigning roles/accountability. These indeed align with effective practices for successful group work as articulated in the literature, and synthesized by centers for teaching and learning for instructors and students [71-73]. While these practices are not novel, we found it insightful that they were organically surfaced by students as the strategies to pursue. Further, all groups who identified these strategies also actively and intentionally carried them out, and had something positive to say about their effect on the group experience and learning. This supports the literature that when group members are given space and agency to make their own decisions and action plans they are more likely to follow through. When groups have autonomy, as these groups did, they also take ownership of their work. As an example, students reported that they were proud of the work they turned in. Group autonomy contributes to effective collaboration in the context of higher education, and is a factor that contributes to positive interdependence [30,74].

The qualitative data allowed for nuance around student thinking which provided greater insight and understanding of the challenges that groups faced and the rationale behind groups' strategies. For example, one of the main strategies identified by student groups was assigning roles. One might assume this strategy was borne of frustration of some students and would primarily be about reducing the number of "free-riders", the group members who did little or nothing and still received the credit. What we found was that the motivations for this strategy were numerous and reflected genuine interest in establishing a team orientation. It is true, for a few, the goal was to address a dynamic in which one or more group members were not (or perceived not to be) "pulling their weight", doing their fair share of the work. However, groups identified other challenges that were addressed by assigning roles including relieving confusion as to who is/will do what. Group members learned that sometimes peers did not contribute not because they did not feel like it or were lazy but because they were not sure in what ways they could be the most useful and/or what was already being done by group members and what was left to be done.

Additional reasons for assigning roles included using limited time better; drawing on individual strengths, and as a way to invite and support the participation of all members. This rationale reflects positive interdependence, where group members recognize that each member has something to 
contribute and that contribution is essential to the success of the group. It is also indicative of another important condition for CL success, promotive interaction. In this rationale, students were encouraging and facilitating one another's efforts. Evidence of other forms of positive interdependence and promotive interaction surfaced in the data analysis [14]. Group members noted the importance of effective communication (developing their own plans for this) for making sure everyone was heard, knew what was happening, listening to everyone's ideas before making a plan, and helping others by explaining concepts when someone did not understand.

Other strategies identified included individual preparation, time management, and proofreading, focused more on overarching career readiness skills. That said, we observed links between what we consider to be more individualized skills and the group aspect of the assignments. In multiple responses, students articulated a need to prepare individually ahead of time in order to be able to contribute to the group during the labs. Other students identified their (and sought to discover others') academic and personal strengths as areas in which they could/did contribute to the larger group. For instance, one student identified editing as a strength, and offered to take on that role for the group. These reports provide further evidence that conditions necessary for effective CL were in place as outlined by Johnson and Johnson: positive interdependence, individual accountability, and personal responsibility for contributing to the group's success [14].

Students' reported effects of these activities were another indicator of if and how the intervention improved the learning of chemistry, the development of cross-cutting competencies, and the improvement of the group work experience. Of the groups that implemented their strategies, all of them reported positive effect(s). Most notably, students reported that project and time management improved. Groups also reported that they were more prepared for the lab and recognized that their collective understanding of the content increased as did their academic performance. There are many students that do not like group work because they have had a negative experience so having students go through the process of identifying a problem, establishing a solution and observing its effects, and seeing success in this process is critical for recognition of their own self efficacy and agency in affecting the nature and success of the group experience.

A theme on the effects of groups' strategies (Table 3) that we would like to highlight is that of inclusion. Multiple groups implemented strategies that lead to explicit and intentional efforts to be more inclusive of all group members. This theme included codes such as ensuring that everyone was able to share their ideas, that all voices were invited and heard, that no one was left behind, and increased confidence of all group members. Additionally, we observed that the use of terms in the effects table are indicative of inclusion, such as "we", "our", "all", "everyone", "collective". This is not surprising because when the conditions of CL are established (e.g., positive interdependence, promotive interactions), it is an inherently inclusive teaching practice. These results provide additional evidence that the newly implemented activities promoted these conditions. The authors became acutely aware of how $\mathrm{CL}$ is a method that facilitates the students' own awareness of inclusive behaviors, and the value and impact they have on creating effective group work experiences. Many of the groups' responses illustrate how students themselves actively promoted practices that brought every group member into the process as a valued contributor to the outcome. Overall, groups reported that the strategies they implemented lead to a more positive group experience: reduced stress, better communication, and things running smoother.

\subsection{Did Students Find Value in the Activities?}

To answer this question, we took into account the students' participation rate, their submitted responses, and the end of semester evaluations. In doing so, we were able to triangulate the data which ultimately affirmed our interpretations above. Combined, these multiple indicators suggest that students found value in these activities. First, 95\% (18 of the 19 groups we studied) participated in the activities, when it was not a course requirement. Second, the responses did not come across as flippant or insincere. On the contrary, they were meaningful to the groups which is supported by 
the completion of the activities, the tone of the writing, and the articulated effects. Finally, in the end of semester evaluation, the students were asked two questions relating to their experience with the check-ins. To the first question, "I believe I learned valuable skills by working in a group this semester that can be applied outside of chemistry", 74\% of respondents either agreed or strongly agreed. The second question was, "Overall, I think the group activities are worthwhile and I would recommend continuing them for future semesters", and to that $58 \%$ of respondents agreed or strongly agreed. These responses are overall positive and affirm the interpretations thus far, but they do leave room for improvement, and offer another area for the genchem team to reflect upon the implementation of future activities.

Finally, we were able to glean additional insight to this question by looking through some additional students' responses to the individual reflection activity that was not part of this study (described above). Students were asked to individually think and write a response to the following prompts, among others: Did you learn something about critical skills or building blocks for effective communication in groups or for project management? How are these skills transferable to other settings? We had a lower response rate to this particular activity, but of the responses, again, they were thoughtful, articulate, and insightful. Participants identified specific skills and insights gained, and acknowledged their transferability and relevance to other aspects of their lives-other classes, social settings, and future employment. With these different data sources, we are able to say that most students found value in these activities and recognize that they are learning/practicing foundational competencies that are essential for their present and future success.

\subsection{What Insight Does This Offer Instructors, Lab Coordinators, and Program Directors?}

First, the facilitated opportunities and space for students to discuss their group dynamics had a positive impact on students' learning of chemistry and the development of skills associated with teamwork. It also had a positive effect on the group work experience, and contributed to an inclusive environment. Hence, there is too much at stake to not attend to student interactions and dynamics, in collaborative learning. Second, implementation fidelity on the part of the instructor is critical as we have seen by a difference in the participation rate when we look across all sections. If one group did not do them, all groups did not do them, suggesting that instructors implemented (or failed to implement) the activities with varying degrees of buy-in and facilitation skills. For program directors and coordinators, these results highlight the importance of providing rationale and training for the implementation of these activities, otherwise the benefits of $C L$ are not leveraged for all students.

A third source of insight for instructors, especially new instructors, is the list of challenges that the groups experienced. Knowing what students struggle with is valuable information for instructors so they know what to look for and monitor. General chemistry lab is a difficult course for students with multiple aspects to keep track of-the course itself, the complex experiments, associated assignments, quizzes, lab reports, and presentations. Therefore, offering guidance and support from the very beginning is important, especially in a complex course such as genchem. Instructors can share this information from the beginning letting students know that these are the strategies previous groups identified, used, and had positive affect. This will not, however, negate the need for or value of group reflection activities, as there are always ways groups can improve and grow, and the process of reflection on group functioning is an important condition for group success [14].

\section{Conclusions}

There are many barriers to promoting and implementing skilled facilitation of student interactions-from magical thinking to content-heavy curriculum, to a lack of experience. Our findings add to the mountain of evidence that supports the need for quality and frequent student interactions and calls for instructors to move beyond these barriers. In general chemistry's inquiry-based labs, students are required to work through a process whereby they develop an experimental plan, implement it, reflect on their data, revise as needed, etc. This same expectation was also extended to the collaborative process to improve and expand on the learning outcomes of collaboration. We demonstrated that 
implementing reflective group work activities is feasible in a large general chemistry course that has many complexities. The genchem team was able to identify effective group work practices, clearly articulate their rationale, and integrate them into the existing course structure. These activities were not add-ons, but rather critical to meeting articulated learning outcomes of the course. Reassuringly, while this work requires a commitment on the part of instructors, it does not require an overhaul of the whole course. Most importantly, we found that students learned valuable strategies to overcome their group challenges and that these strategies had positive effects on their content learning, skill development associated with effective collaboration, the group work experience, and created an inclusive learning environment. These findings are especially significant given the need to support underrepresented students in our increasingly diverse classrooms.

This work cannot be done by the genchem team alone because it is but one piece of a larger whole. If every instructor, from chemistry to physics to Spanish to history to math seizes the opportunities of $\mathrm{CL}$ and identifies the ways they can model and promote effective interactions, then over the course of a college career, students will have many opportunities to reflect on, practice, and hone these competencies that are essential for a successful future. Our work is also not done. The genchem team will continue its restless practice by using this research to inform the next iteration and implementation of the activities outlined and discussed. The foci will be on improving instructor fidelity with new revisions to our teaching assistant training. The team will also reflect on how to increase the value students see and experience with the activities.

We recognize that every course is unique with its own set of challenges and opportunities, so the model presented here cannot be directly applied to every course. There is never a one size fits all. However, we hope we have provided one pathway and/or motivation to find space to integrate this kind of work into your own classrooms, in whatever form it may take. By actively and intentionally supporting the process of collaboration, you are supporting enhanced content learning, among many other essential outcomes, and promoting and establishing an inclusive learning environment. For the genchem team, identifying and integrating reflective activities was a journey and continues to be so. We invite you to join in our restlessness.

Author Contributions: Conceptualization, coding, writing-original draft preparation, writing-review and editing, H.L., A.S. All authors have read and agreed to the published version of the manuscript.

Funding: This research received no external funding.

Acknowledgments: We would like to thank all the members who were a part of the International Student Academic Integration faculty cohort. In particular, we would like to acknowledge Driessen's support and mentorship throughout this process. The Internationalizing Teaching and Learning cohort also contributed to the development of the activities presented here. We would also like to thank Amy Lee who been a constant support, advocate, and friend throughout this whole process. Lastly, we would like to thank Sue Staats and Bismark Akoto for their writing support.

Conflicts of Interest: The authors declare no conflict of interest.

\section{Appendix A}

\section{Group Check-in \#1}

Since this lab depends so heavily on group work, we want to encourage and make sure that you're discussing as a group how things are going throughout the semester.

Take 2-3 min to reflect on the questions below individually. Once everyone has finished reflecting individually, take turns sharing your answers with other group members. As a group, come to an agreement about something you will change and how you're going to do it for the next project. Edit the entry below and submit as a group when finished.

1. What is the one change your group will make to improve your performance?

2. It's easy to identify what you need to change but harder to identify how to fix it. So what is your group going to DO to solve the problem or improve? 


\section{Group Check-in \#2}

Review your responses from the first check-in.

1. What did you do to implement your plan of improvement?

2. IF you implemented the plan:

- What specific effect did this have? Give examples. Are there any additional changes you think your group needs to make?

- If you did not follow through with your plan or changes: Why not? What happened? How will you change that for the next project? Include actionable steps.

\section{References}

1. Associates, H.R. Falling Short? College Learning and Career Success; Association of American Colleges and Universities: Washington, DC, USA, 2015.

2. Johnson, D.W.; Johnson, R.T.; Smith, K. The State of Cooperative Learning in Postsecondary and Professional Settings. Educ. Psychol. Rev. 2007, 19, 15-29. [CrossRef]

3. van Boxtel, C.; van der Linden, J.; Kanselaar, G. Collaborative learning tasks and the elaboration of conceptual knowledge. Learn. Instr. 2000, 10, 311-330. [CrossRef]

4. Linton, D.L.; Farmer, J.K.; Peterson, E. Is Peer Interaction Necessary for Optimal Active Learning? CBE Life Sci. Educ. 2014, 13, 243-252. [CrossRef] [PubMed]

5. Khosa, D.K.; Volet, S.E. Promoting effective collaborative case-based learning at university: A metacognitive intervention. Stud. High. Educ. 2013, 38, 870-889. [CrossRef]

6. Harper, S.R. Not by accident: Intentionality in diversity, learning, and engagement. In Creating Inclusive Campus Environments for Cross-Cultural Learning and Student Engagement; NASPA: Tampa, FL, USA, 2008; ISBN 9780931654534.

7. Lee, A.; Poch, R.K.; O'Brien, M.K.; Solheim, C. Teaching Interculturally: A Framework for Integrating Disciplinary Knowledge and Intercultural Development; Stylus Publishing: Sterling, VA, USA, 2017; ISBN 9781620363829.

8. Peters, B.; Anderson, M. Supporting Non-Native English Speakers at the University of Minnesota: A Survey of Faculty \& Staff; University of Minnesota: Minneapolis, MN, USA, 2017.

9. Lee, A.; Poch, R.; Shaw, M.; Williams, R.D. Engaging Diversity in Undergraduate Classrooms: A Pedagogy for Developing Intercultural Competence, 38th ed.; Jossey-Bass: San Francisco, CA, USA, 2012.

10. Johnson, D.W.; Johnson, R.T. Making cooperative learning work. Theory Pract. 1999, 38, 67-73. [CrossRef]

11. Panitz, T. The Motivational Benefits of Cooperative Learning. In Motivation from Within: Approaches for Encouraging Faculty and Students to Excel: New Directions for Teaching and Learning; Theall, M., Ed.; Josey-Bass Publishing: San Francisco, CA, USA, 1999; pp. 59-68. ISBN 978-0-787-94875-7.

12. Springer, L.; Stanne, M.E.; Donovan, S.S. Effects of Small-Group Learning on Undergraduates in Science, Mathematics, Engineering, and Technology: A Meta-Analysis. Rev. Educ. Res. 1999, 69, 21-51. [CrossRef]

13. Dees, R.L. The Role of Cooperative Learning in Increasing Problem-Solving Ability in a College Remedial Course. J. Res. Math. Educ. 1991, 22, 409-421. [CrossRef]

14. Johnson, D.W.; Johnson, R.T. Learning Together and Alone: Cooperative, Competitive, and Individualistic Learning, 5th ed.; Allyn and Bacon: Boston, MA, USA, 1999; ISBN 9780205287710.

15. Johnson, D.W.; Johnson, R.T. Cooperation and Competition: Theory and Research; Interaction Book Company: Edina, MN, USA, 1989; ISBN 0-939603-10-1.

16. Laal, M.; Ghodsi, S.M. Benefits of collaborative learning. Procedia-Soc. Behav. Sci. 2012, 31, 486-490. [CrossRef]

17. Bowman, N.A. College Diversity Experiences and Cognitive Development: A Meta-Analysis. Rev. Educ. Res. 2010, 80, 4-33. [CrossRef]

18. Deardorff, D.K. Identification and Assessment of Intercultural Competence as a Student Outcome of Internationalization. J. Stud. Int. Educ. 2006, 10, 241-266. [CrossRef]

19. Hurtado, S. Linking Diversity and Educational Purpose: How Diversity Affects the Classroom Environment and Student Development; Harvard Education Publishing Group: Cambridge, MA, USA, 2001.

20. Prince, M. Does Active Learning Work? A Review of the Research. J. Eng. Educ. 2004, 93, 223-231. [CrossRef] 
21. Lindsey Parsons, R. The Effects of an Internationalized University Experience on Domestic Students in the United States and Australia. J. Stud. Int. Educ. 2009, 14, 313-334. [CrossRef]

22. Yefanova, D.; Woodruff, G.; Kappler, B.; Johnstone, C. Study of the Educational Impact of International Students in Campus Internationalization at the University of Minnesota; Global Programs and Strategy Alliance: Minneapolis, MN, USA, 2015.

23. Tinto, V. Enhancing Learning Via Community. NEA High. Educ. J. 1997, 6, 53-54.

24. Ghaith, G.M. The relationship between cooperative learning, perception of social support, and academic achievement. System 2002, 30, 263-273. [CrossRef]

25. Gurin, P.; Dey, E.; Hurtado, S.; Gurin, G. Diversity and Higher Education: Theory and Impact on Educational Outcomes. Harv. Educ. Rev. 2002, 72, 330-367. [CrossRef]

26. Kessler, R.C.; Price, R.H.; Wortman, C.B. Social factors in psychopathology: Stress, social support, and coping processes. Annu. Rev. Psychol. 1985, 36, 531-572. [CrossRef]

27. Modaber, H.; Bayan Far, F. The Effects of Cooperative Learning on Students Self-Esteem. Eur. J. Soc. Sci. Stud. 2017, 2, 142-150.

28. Poellhuber, B.; Chomienne, M.; Karsenti, T. The effect of peer collaboration and collaborative learning on self-efficacy and persistence in a learner-paced continuous intake model. J. Distance Educ. 2008, 22, 41-62.

29. Johnstone, C.; Yefanova, D.; Woodruff, G.; Montgomery, M.; Kappler, B. "It Would Be Better If You Can Hang Out with Different People": An Examination of Cross-National Interaction in Postsecondary Classrooms. J. Teach. Learn. 2018, 12, 23-37. [CrossRef]

30. Scager, K.; Boonstra, J.; Peeters, T.; Vulperhorst, J.; Wiegant, F. Collaborative Learning in Higher Education: Evoking Positive Interdependence. CBE Life Sci. Educ. 2016, 15, ar69. [CrossRef]

31. Kuh, G.; Kinzie, J.; Buckley, J.; Ed, B.; Ed, H. Piecing Together the Student Success Puzzle: Research, Propositions, and Recommendations. ASHE Higher Education Report, Volume 32, Number 5. ASHE High. Educ. Rep. 2007, 32, 1-182.

32. Smith, M.E.; Hinckley, C.C.; Volk, G.L. Cooperative learning in the undergraduate laboratory. J. Chem. Educ. 1991, 68, 413. [CrossRef]

33. Vázquez-García, M. Collaborative-group testing improves learning and knowledge retention of human physiology topics in second-year medical students. Adv. Physiol. Educ. 2018, 42, 232-239. [CrossRef] [PubMed]

34. Luo, J.; Jamieson-Drake, D. Examining the Educational Benefits of Interacting with International Students. J. Int. Students 2013, 3, 85-101.

35. Hausmann, L.R.M.; Ye, F.; Schofield, J.W.; Woods, R.L. Sense of Belonging and Persistence in White and African American First-Year Students. Res. High. Educ. 2009, 50, 649-669. [CrossRef]

36. Smith, J.L.; Cech, E.; Metz, A.; Huntoon, M.; Moyer, C. Giving back or giving up: Native American student experiences in science and engineering. Cult. Divers. Ethn. Minor. Psychol. 2014, 20, 413-429. [CrossRef]

37. Casey, M.E.; Murphy Robinson, S. Neuroscience of Inclusion: New Skills for New Times; Outskirts Press: Denver, CO, USA, 2017; ISBN 1432787225.

38. Institute of International Education; Bureau of Educational and Cultural Affairs. Open Doors 2019; Institute of International Education: Washington, DC, USA, 2019.

39. American Council on Education; American Council of International Higher Education. International Briefs for Higher Education Leaders; American Council on Education: Washington, DC, USA, 2019.

40. Stump, G.S.; Hilpert, J.C.; Husman, J.; Chung, W.; Kim, W. Collaborative Learning in Engineering Students: Gender and Achievement. J. Eng. Educ. 2011, 100, 475-497. [CrossRef]

41. Griffith, A.L. Persistence of women and minorities in STEM field majors: Is it the school that matters? Econ. Educ. Rev. 2010, 29, 911-922. [CrossRef]

42. Ishitani, T.T. Studying Attrition and Degree Completion Behavior among First-Generation College Students in the United States. J. Higher Educ. 2006, 77, 861-885. [CrossRef]

43. Chen, X.; Soldner, M. STEM Attrition: College Students' Paths into and out of STEM Fields; National Center for Education Statistics, Institute of Education Sciences, U.S. Department of Education: Washington, DC, USA, 2014; pp. 1-96.

44. Espinosa, L.L. Pipelines and pathways: Women of color in undergraduate STEM majors and the college experiences that contribute to persistence. Harv. Educ. Rev. 2011, 81, 209-240. [CrossRef] 
45. Allen-Ramdial, S.-A.A.; Campbell, A.G. Reimagining the Pipeline: Advancing STEM Diversity, Persistence, and Success. Bioscience 2014, 64, 612-618. [CrossRef] [PubMed]

46. Palmer, R.T.; Maramba, D.C.; Dancy, T.E. A Qualitative Investigation of Factors Promoting the Retention and Persistence of Students of Color in STEM. J. Negro Educ. 2011, 80, 491-504.

47. Treisman, P.M. A Study of the Mathematics Performance of Black Students at the University of California, Berkeley; University of California: Berkeley, CA, USA, 1985.

48. Mestenhauser, J.A.; Global Programs and Strategy Alliance. Reflections on the Past, Present, and Future of Internationalizing Higher Education: Discovering Opportunities to Meet the Challenges; Global Programs and Strategy Alliance at the University of Minnesota: Minneapolis, MN, USA, 2011; ISBN 9780984758302.

49. Piaget, J. The Psychology of Intelligence; Harcourt and Brace: New York, NY, USA, 1950.

50. Mezirow, J. Transformative Dimensions of Adult Learning; Wiley: Hoboken, NJ, USA, 1991; ISBN 9781555423391.

51. (AAC\&U), A. of A.C. and U. College Learning for a New Global Century; Association of American Colleges and Universities: Washington, DC, USA, 2007.

52. University of Minnesota. Board of Reagents Policy: Mission Statement; University of Minnesota: Minneapolis, MN, USA, 2008; pp. 1-2.

53. Gottschall, H.; Garcia-Bayonas, M. Student Attitudes towards Group Work among Undergraduates in Business Administration, Education and Mathematics. Educ. Res. Q. 2008, 32, 3.

54. Marks, M.B.; O'Connor, A.H. Understanding Students' Attitudes About Group Work: What Does This Suggest for Instructors of Business? J. Educ. Bus. 2013, 88, 147-158. [CrossRef]

55. Chang, Y.; Brickman, P. When Group Work Doesn't Work: Insights from Students. CBE Life Sci. Educ. 2018, 17, ar42. [CrossRef]

56. Chang, M.J.; Chang, J.C.; Ledesma, M.C. Beyond magical thinking: Doing the real work of diversifying our institutions. About Campus 2005, 10, 9-16. [CrossRef]

57. Milem, J.; Chang, M.; Antonio, A. Making Diversity Work on Campus: A Research-Based Perspective; Association of American Colleges and Universities: Washington, DC, USA, 2012.

58. Bennett, J.M.; Bennett, M.J. Developing Intercultural Sensitivity: An Integrative Approach to Global and Domestic Diversity. In Handbook of Intercultural Training; SAGE Publications, Inc.: Thousand Oaks, CA, USA, 2004; pp. 147-165.

59. Williams, R.D.; Lee, A. Internationalizing Higher Education: Critical Collaborations Across the Curriculum; Sense Publishers: Rotterdam, The Netherlands, 2015.

60. Mazur, E. Farewell, Lecture? Science 2009, 323, 50-51. [CrossRef]

61. Halpern, D.F.; Hakel, M.D. Applying the science of learning to the university and beyond: Teaching for long-term retention and transfer. Chang. Mag. High. Learn. 2003, 35, 36-41. [CrossRef]

62. Arkoudis, S.; Watty, K.; Baik, C.; Yu, X.; Borland, H.; Chang, S.; Lang, I.; Lang, J.; Pearce, A. Finding common ground: Enhancing interaction between domestic and international students in higher education. Teach. High. Educ. 2013, 18, 222-235. [CrossRef]

63. Baker, P. Creating Learning Communities: The Unfinished Agenda. In The Social Works of Higher Education; Pescosolido, B.A., Aminzade, R., Eds.; Pine Forge Press: Thousand Oaks, CA, USA, 1999; pp. 90-100.

64. Cox, M.D. Introduction to faculty learning communities. New Dir. Teach. Learn. 2004, 2004, 5-23. [CrossRef]

65. Lee, A.; Poch, R.; Smith, A.; Delehanty Kelly, M.; Leopold, H. Intercultural Pedagogy: A Faculty Learning Cohort. Educ. Sci. 2018, 8, 177. [CrossRef]

66. Glaser, B.G.; Strauss, A.L. Theoretical Sampling. In The Discovery of Grounded Theory; Aldine: Chicago, IL, USA, 1967; ISBN 0-202-30260-1.

67. Urquhart, C. Introduction. In Grounded Theory for Qualitative Research: A Practical Guide; SAGE Publications: Thousand Oaks, CA, USA, 2013; p. 9. ISBN 9781446289716.

68. Strauss, A.; Corbin, J. Basics of Qualitative Research: Techniques and Procedures for Developing Grounded Theory, 2nd ed.; Sage Publications, Inc.: Thousand Oaks, CA, USA, 1998; ISBN 0-8039-5939-7.

69. Patton, M.Q. Enhancing the quality and credibility of qualitative analysis. Health Serv. Res. 1999, 34, 1189-1208. [PubMed]

70. Ambrose, S.A.; Bridges, M.W.; DiPietro, M.; Lovett, M.C.; Norman, M.K.; Mayer, R.E. How Learning Works: Seven Research-Based Principles for Smart Teaching; Jossey-Bass Higher and Adult Education Series; Wiley: Hoboken, NJ, USA, 2010; ISBN 9780470617601. 
71. Center for Educational Innovation. Faculty Guide to Team Projects. Available online: https://cei.umn.edu/ faculty-guide (accessed on 26 November 2019).

72. Center for Educational Innovation. Surviving Group Projects. Available online: https://teamwork.umn.edu/ (accessed on 26 November 2019).

73. Brame, C.J.; Biel, R. Setting Up and Facilitating Group Work: Using Cooperative Learning Groups Effectively. Available online: http://cft.vanderbilt.edu/guides-sub-pages/setting-up-and-facilitating-group-work-usingcooperative-learning-groups-effectively/ (accessed on 27 November 2019).

74. Zimmerman, B.J.; Bandura, A.; Martinez-Pons, M. Self-Motivation for Academic Attainment: The Role of Self-Efficacy Beliefs and Personal Goal Setting. Am. Educ. Res. J. 1992, 29, 663-676. [CrossRef]

C 2019 by the authors. Licensee MDPI, Basel, Switzerland. This article is an open access article distributed under the terms and conditions of the Creative Commons Attribution (CC BY) license (http://creativecommons.org/licenses/by/4.0/). 